\section{Molecular constructivity}

SIR - Dan Graur accused us in your pages of "molecular deconstructivism". But only his letter ${ }^{1}$ is destructive, because it failed to address the conceptual issues of our paper ${ }^{2}$. Instead, Graur limits himself to criticizing our terminology. Moreover, in an apparent attempt to ridicule us, he then "invents", but imputes to us, additional terms and applications that we clearly excluded from consideration, thus grossly distorting our effort. Most scholars will agree that our nomenclature was not intended either to amuse ourselves or to vex our colleagues, but rather to identify and explain concepts that now have no names but are important for understanding the evolution of genomic sequences and structures.

First, we addressed the need for a more general term for any definable stretch of polynucleic acid (nuon). As recently brought to our attention, Nei and Tajima responded to the need for a similar definition more than a dozen years ago when they proposed the term nucleon (borrowed from nuclear physics) to describe definable nucleic acid sequence in a more general way ${ }^{3}$. Unfortunately, the term did not take hold, perhaps because another field already used the same name in such a different sense.

Second, the concepts of potaptation, exaptation, adaptation and nonaptation, and in particular the cross-convertibility between these different stages, with resulting increase of the genomic flux, increasingly prove to illustrate vital evolutionary principles. It is therefore logical (and helpful) to integrate these concepts into aspects of the genomic nomenclature (see figure).

This allows us, for example, to give non-genic DNA elements (formerly considered junk DNA as in the case for middle repetitive elements) the attention that they deserve, given their role in shaping future genes or parts thereof including their regulation ${ }^{4}$.

Perhaps we should envy physics, where it appears that novel concepts and their accompanying nomenclature receive serious attention rather than antiintellectual ridicule.

\section{Jürgen Brosius}

Mount Sinai Medical Center,

One Gustave L Levy Place,

New York,

New York 10029, USA

Stephen Jay Gould

Museum of Comparative Zoology,

Harvard University,

Cambridge,

Massachusetts 02138, USA

1. Graur, D. Nature 363, 490(1993).

2. Brosius, J. \& Gould, S. J. Proc, natn. Acad. Sci. U.S.A. 89 10706-10710 (1992).

3. Nei. M. \& Tajima, F. Genetics 97, 145-163 (1981)

4. Brosius. J. Science 251, 753 (1991)

5. Gilbert, W. Nature 271, 501 (1978).

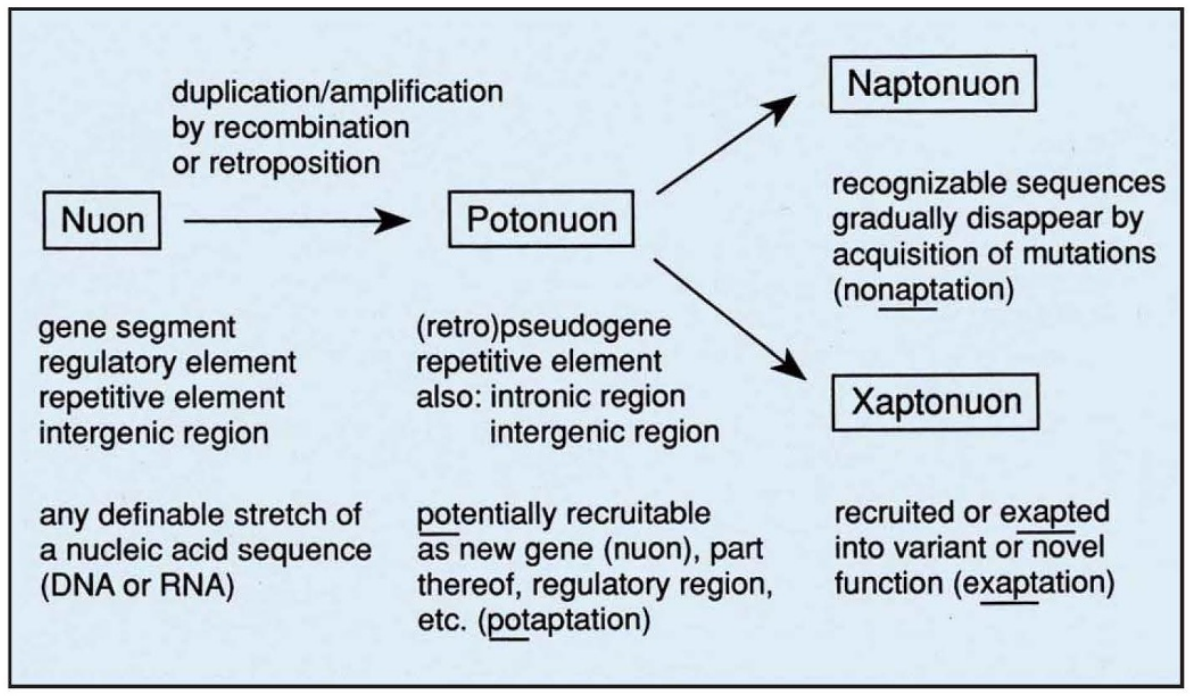

Chromosome segments, including entire genes, are not the only elements that can be amplified within a genome. Repetitive elements, for example, that are not considered genes but can be defined as nuons, are generated by efficient amplification, for example, through retroposition. The new nuon may have a variety of impacts on a possible neighbouring gene including its expression. Each nuon, therefore, has the potential to become part of an adjacent gene, including, but not limited to a new acceptor or donor site for splicing, part of a new exon, transcriptional enhancer or polyadenylation signal. As a result of this potential, a new nuon is always a potonuon. If indeed exapted into a new role, it may be termed a xaptonuon. If the recognizable sequence, as probably in most cases, disappears after a long enough evolutionary time span due to mutational attrition, it is considered a nonaptation and thus a naptonuon. The latter scenario, however, does not preclude the later exaptation of such a neutral drifting sequence into a new role: An intronic sequence, for example, may be recruited as a novel exon in an existing gene ${ }^{5}$

\section{No to "genethics"}

SIR - The provocatively titled "New genetics means no new ethics" 1 makes the important point that society does not need new ethics to cope with the impact of genetic technology. There is no inherent clash between genetics and human values as some books, including one under the title Genethics ${ }^{2}$, would like to have us believe. This concept should be stopped because almost all the issues raised by application of genetics are not novel.

What is needed is a revival and renewed discussion of ethical values as society interacts with technology, and reassurance that scientists are responsible, as we have seen in recent issues of Nature $e^{3-5}$. Applications of genetics have been a useful catalyst for this process ${ }^{6}$. Sequencing of the human genome may not create new ethical dilemmas, or necessarily make them worse, as your leading article points out, but the sheer number of diseaserelated genes identified will make the number of such dilemmas greater. The number of known "early-death" related genes will increase so that it may even be impractical for insurance companies to identify individual risk, let alone the ethical arguments ${ }^{7}$. Life will be more complex, even the supposedly simple case of imposing higher insurance fees on smokers will become more cloudy should we find strong genetic determinants for drug addiction, to add to the environmental determinants we already know.

In the final paragraph of the article, Maddox concludes that it is unwise for geneticists to say "never touch the germline". Although geneticists may like to say this, perhaps naively to reassure the public that they have nothing to worry about, over the past two or three years "ethicists" have been seriously revisiting the issue of human germline genetic manipulation ${ }^{8}$. Some want a ban on germline manipulation, but the somatic cell/germline division is less important than the therapy/ cosmetic border. In the easy cases of severe disease, safe and nonexpensive germline gene therapy can make sense. We should encourage discussion of these complex issues and, in the real world, never say never.

Darryl Macer

Institute of Biological Sciences,

University of Tsukuba,

Ibaraki 305, Japan

1. Nature 364, 97 (1993).

2. Suzuki, D. \& Knudtson, P. Genethics: The Clash Between the New Genetics and Human Values (Hanard University Press, Boston, 1989)

3. Nature 359.770 (1992).

4. Nature 362, 491-492 (1993)

5. Nature 363, 203-204 (1993)

6. Macer, D. Shaping Genes: Ethics, Law and Science of Using Genetic Technology in Medicine and Agriculture (Eubios Ethics Institute, Christchurch, 1990).

7. Nature 354, 347 (1991)

8. Juengst, E. T. et al. Human germ-line engineering. Special issue. J. med. Phil. 16, 587-694 (1991). 